\title{
AGE-DEPENDENT CANNIBALISM IN A COLONY OF ALBINO RATS
}

\author{
by \\ CHANDRA MOHAN \\ Department of Zoology, Bangalore University, \\ Bangalore 560001, India
}

Cannibalism in laboratory animals is well known (Hart, 1934; Weaver \& Bird, 1934; Perla \& Sandberg, 1939; Hankin, 1960; Karmurthi, Sreenivasamoorthy \& Parpia, 1972). It has been attributed to maternal nutritional deficiency (Hart, 1934; Carlson \& Hoelzel, 1948; Hankin, 1960), environmental conditions such as over-crowding, boredom and parasitism (Wilson, 1949), toxic substances in the diet (Karmurthi, et al., 1972), or to toxicity produced by an excess of certain vitamins or minerals in the diet (Perla \& Sandberg, 1939). Weaver \& Bird (1934) have attributed cannibalism to the loss of maternal instinct due to disturbances in the physical state of the mother rats. In the present study the effect of maternal age on mortality due to cannibalism and loss of maternal care is considered.

Altogether 240 female Wistar rats were used. They were kept in polypropylene cages fitted with stainless-steel wire-mesh bottoms, and housed in a vermin-proof room maintained at $28 \pm 2^{\circ} \mathrm{C}$. Compressed absorbent cotton was used both as bedding and nesting material. The same commercial diet ('Rat and mouse feed'; Hindustan Lever Ltd, Bombay, India) was fed throughout the experiment.

Depending upon their age at pairing, the rats can be divided into 12 groups, each containing 20 animals. Except for Group 1, the rats were all parous, having produced from 1 to 6 litters. Pregnant rats were separated and individually maintained. From the day of birth up to weaning on Day 21, the young were counted daily between 0900 and 1000 hours. Young that were found partially eaten or missing were classified as 'cannibalised', whilst those found dead but intact were considered to have died from starvation or lack of maternal care.

The results are presented in Table 1 . In the youngest females, paired at 2 to 6 months of age, the incidence of cannibalism was less than $10 \%$, but it rose quite sharply to reach a maximum of $34 \%$ in females paired at 11-11.9 months of age (group 10). The level of deaths attributed to lack of maternal care or starvation remained relatively low (3-8\%) in females paired up to 10 months of age (Groups 1 to 8 ), and then increased dramatically to a peak of $60 \%$ in those paired at 13-13.9 months of age (Group 12). In the 2 oldest 
Table 1. Effect of maternal age on cannibalism in the rat.

each group contains 20 females.

$\%$ deaths before weaning due to

$\begin{array}{rcccc}\text { Group } & \begin{array}{c}\text { Age of female at } \\ \text { pairing (months) }\end{array} & \begin{array}{c}\text { mean litter size } \\ \pm \text { s.d. }\end{array} & \text { cannibalism } & \begin{array}{c}\text { lack of maternal } \\ \text { care/starvation }\end{array} \\ 1 & 2-2.9 & 9.6 \pm 3.00 & 9.40 & 3.20 \\ 2 & 3-3.9 & 11.3 \pm 1.40 & 6.80 & 4.60 \\ 3 & 4-4.9 & 10.9 \pm 2.05 & 4.90 & 3.80 \\ 4 & 5-5.9 & 10.8 \pm 1.87 & 6.00 & 2.95 \\ 5 & 6-6.9 & 8.4 \pm 1.30 & 10.90 & 4.15 \\ 6 & 7-7.9 & 7.8 \pm 0.93 & 14.80 & 4.13 \\ 7 & 8-8.9 & 6.8 \pm 0.96 & 20.40 & 6.15 \\ 8 & 9-9.9 & 6.4 \pm 1.35 & 23.61 & 7.89 \\ 9 & 10-10.9 & 5.8 \pm 0.83 & 23.62 & 19.43 \\ 10 & 11-11.9 & 5.1 \pm 0.90 & 34.00 & 32.40 \\ 11 & 12-12.9 & 4.6 \pm 2.00 & 22.80 & 41.90 \\ 12 & 13-13.9 & 4.2 \pm 1.80 & 22.84 & 60.30\end{array}$

groups lack of maternal care or starvation accounted for 2-3 times as many deaths as did cannibalism. This age-dependent mortality is attributed to a disturbed physiological state of the mothers due to hormonal imbalance. Breeding capacity, e.g. litter size, was also significantly reduced after 9 to 10 months of age.

\section{ACKNOWLEDGEMENTS}

I am grateful to Dr A. R. Kasturi Bai, Head of the Zoology Department of Bangalore University for her encouragement and interest in the work. I am deeply indebted to late Professor K. Pampapathi Rao for suggesting the problem and for guidance. Financial support from the Department of Atomic Energy, Government of India, is gratefully acknowledged.

\section{REFERENCES}

Carlson, A. J. \& Hoelzel, F. (1948). Effect of vegetarian self-reaction diets on reproduction and growth of offsprings of rats. Journal of Nutrition 35, 49.

Hankin, L. (1960). The control of filicidal cannibalism by vitamin $\mathbf{B}_{12}$. Journal of Nutrition $71,188$.

Hart, L. (1934). Cannibalism in fowls associated with a deficiency of animal protein in the diet. Australian Veterinary Journal 10, 23.

Karmurthi, A. S., Sreenivasamoorthy, V. \& Parpia, H. A. B. (1972). Cannibalistic behaviour of mother albino rats fed aflatoxin. Indian Journal of Experimental Biology 10, 307.

Perla, D. \& Sandberg, M. (1939). Metabolic interdependence of vitamin $\mathbf{B}_{1}$ and manganese. Reciprocal neutralization of their toxic effects. Proceedings of the Society for Experimental Biology and Medicine 41, 522.

Weaver, C. H. \& Bird, S. (1934). The nature of cannibalism occurring among adult domestic fowls. Journal of the American Veterinary Medical Association 85, 623.

Wilson, J. E. (1949). The incidence of nutritional diseases in poultry. British Journal of Nutrition 3, 267. 